\title{
Going to Scale: Re-Engineering Systems for Primary Care Treatment of Depression
}

\author{
Allen J. Dietrich, $M D^{\prime}$ \\ Thomas E. Oxman $M D^{1}$ \\ Jobn W. Williams, Jr, MD, MHSC ${ }^{2}$ \\ Kurt Kroenke, $\mathrm{MD}^{3}$ \\ H. Charles Scbulberg, $P b D^{4}$ \\ Martha Bruce, $\mathrm{PbD}^{4}$ \\ Sheila L. Barry ${ }^{1}$ \\ 'Department of Community and Family \\ Medicine, Dartmouth Medical School, \\ Hanover, $\mathrm{NH}$ \\ ${ }^{2}$ Center for Health Services Research in \\ Primary Care and the Division of General \\ Internal Medicine, Durham Veterans Affairs \\ Medical Center and Duke University, \\ Durham, NC \\ ${ }^{3}$ Regenstrief Institute for Health Care and \\ Indiana University School of Medicine, \\ Indianapolis, Ind \\ ${ }^{4}$ Weill Medical College of Cornell \\ University, White Plains, NY
}

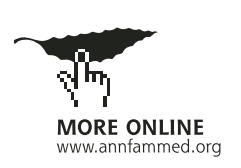

Conflicts of interest: none reported

\section{CORRESPONDING AUTHOR}

Allen J. Dietrich, MD

Department of Community and Family Medicine

HB 7250, Dartmouth Medical School

Hanover, NH 03755.

allen.dietrich@dartmouth.edu

\begin{abstract}
BACKGROUND Recent trials have shown improved depression outcomes with chronic care models. We report the methods of a project that assesses the sustainability and transportability of a chronic care model for depression and change strategy.
\end{abstract}

METHODS In a randomized controlled trial (RCT), a clinical model for depression was implemented through a strategy supporting practice change. The clinical model is evidence based. The change strategy relies on established quality improvement programs and is informed by diffusion of innovations theory. Evaluation will address patient outcomes, as well as process of care and process of change.

RESULTS Five medical groups and health plans are participating in the trial. The RCT involves 180 clinicians in 60 practices. All practices assigned to the clinical model have implemented it. Participating organizations have the potential to disseminate this clinical model of care to 700 practices and 1,700 clinicians.

CONCLUSIONS It is feasible to implement the clinical model and change strategy in diverse practices. Follow-up evaluation will determine the impact, sustainability, and potential for dissemination. Materials are available through http://www. depression-primarycare.org; more in-depth descriptions of the clinical model and change strategy are available in the online-only appendixes to this article.

Ann Fam Med 2004;2:301-304. DOI: 10.1370/afm.102.

\section{INTRODUCTION}

Tmproving depression outcomes in primary care has been a public health priority for at least a decade ${ }^{1}$ but remains elusive. ${ }^{2}$ Although research has shown improved outcomes with telephone care management and closer primary care and mental health collaboration, ${ }^{3-11}$ the potential for dissemination and sustainability of these strategies has not been established.

The MacArthur Foundation has charged a group of clinicians and researchers to make a difference on a national scale in the primary care management of depression. ${ }^{12-23}$ For more on this work, see Appendix 1, which can be found online only as supplemental data at http://www. annfammed.org/cgi/content/full/2/4/301/DC1. Additional momentum comes from the US Preventive Services Task Force (USPSTF) through its endorsement of depression screening in adults ${ }^{24}$ "in clinical practices that have systems in place to assure accurate diagnosis, effective treatment, and careful follow up." They state, "Benefits from screening are unlikely to be realized unless such systems are functioning well."

The jump from the page to the practice is long. ${ }^{25}$ This report describes (1) a broadly applicable evidence-based clinical model of depression care, (2) a practice change strategy, and (3) the methods of a project to evaluate their impact.

\section{METHODS}

The Re-Engineering Systems for Primary Care Treatment of Depression (RESPECT-Depression) project includes a randomized controlled 
trial (RCT) and subsequent evaluations of sustainability and dissemination of information. The design is described in Appendix 2, available online only as

supplemental data at http://www.annfammed. in org/cgi/content/full/2/4/301/DC1.

Health care organizations (HCOs) invited to

\section{Figure 1. The Three Component Model.}

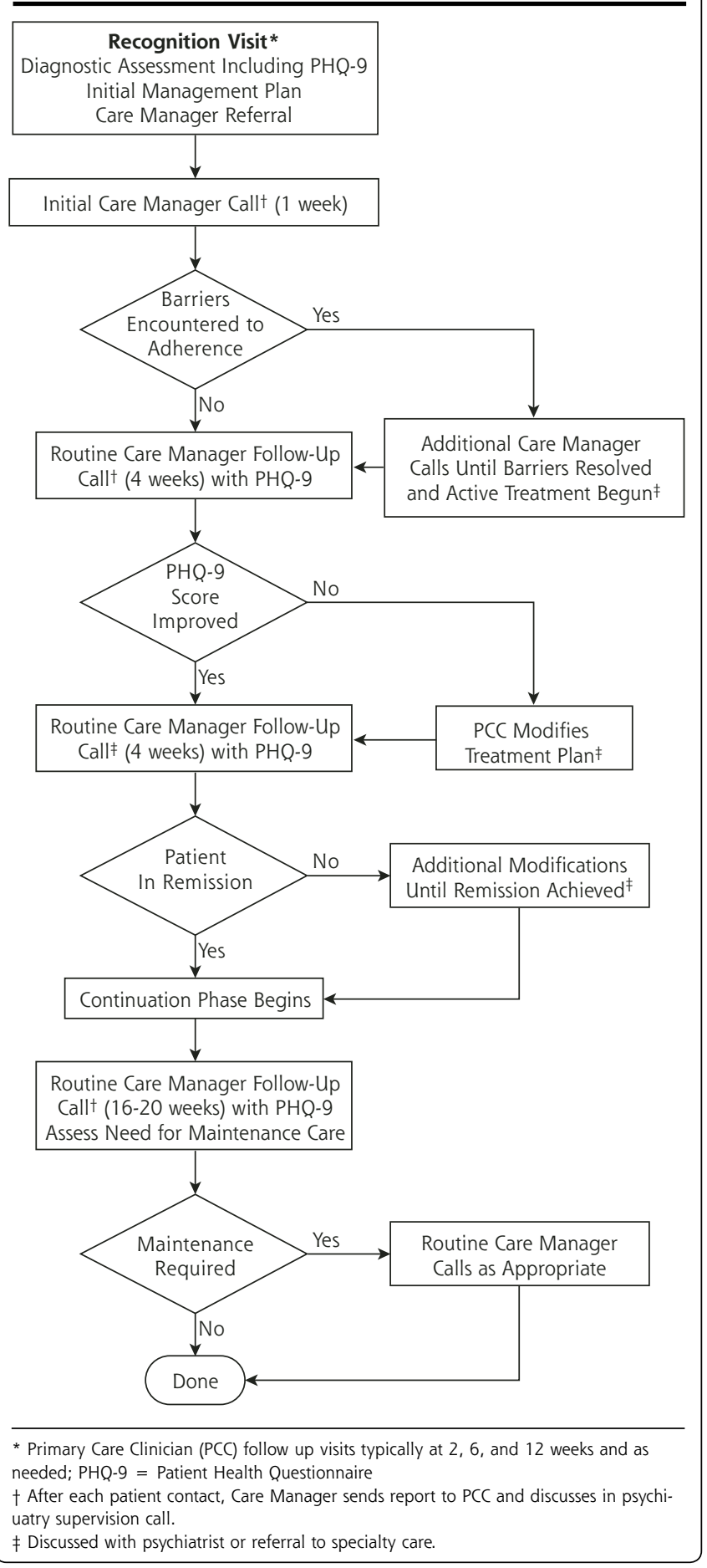

participate included medical groups and health plans that provide quality improvement support to affiliated practices. HCO leaders were willing to commit to ongoing support for the clinical model and to disseminate it to additional practices through the practice change strategy if the model was beneficial.

\section{The Clinical Model}

The Three Component Model (TCM) enhances care $^{17}$ by providing a system for depression management as recommended by the USPSTF (Figure 1). Components include care management, collaboration between mental health and primary care professionals, and preparation of primary care clinicians and practices to provide systematic depression management. Patient response is monitored across components by using the Patient Health Questionnaire-9 (PHQ-9). ${ }^{26-28}$ Similar systematic approaches have improved preventive care. ${ }^{29-31}$

The primary care clinician is responsible for recognition, diagnostic evaluation, and initial management of depression, as well as follow-up care. Clinicians receive training in the model and are thus prepared to provide systematic care. Patients who agree to participate receive telephone support calls from a practice-based or centrally-based care manager at 1,4 , and 8 weeks after the initial primary care visit and additional telephone calls every 4 weeks thereafter until remission. Through weekly supervision telephone calls, care managers discuss patient contacts with a psychiatrist from their health care organization. Based on these discussions, psychiatrists may provide feedback to primary care clinicians if they have suggestions about management. A more complete description of the clinical model is found in Appendix 3 , available online only as supplemental data at http://www.annfammed.org/cgi/content/ full/2/4/301/DC1).

\section{The Practice Change Strategy}

This strategy supports a process of change for clinicians and practices to apply and maintain the clinical model (Figure 2). Key principles, which derive from diffusion of innovations theory, ${ }^{32}$ include working initially with practices and clinicians that not only have an interest in the innovation and view it as compatible with their needs, values, and resources, but also have the ability to try it with minimal investment and observe its impact. A more complete description can be found in Appendix 4, available online only as supplemental data at http://www.annfammed.org/cgi/ content/full/2/4/301/DC1. 


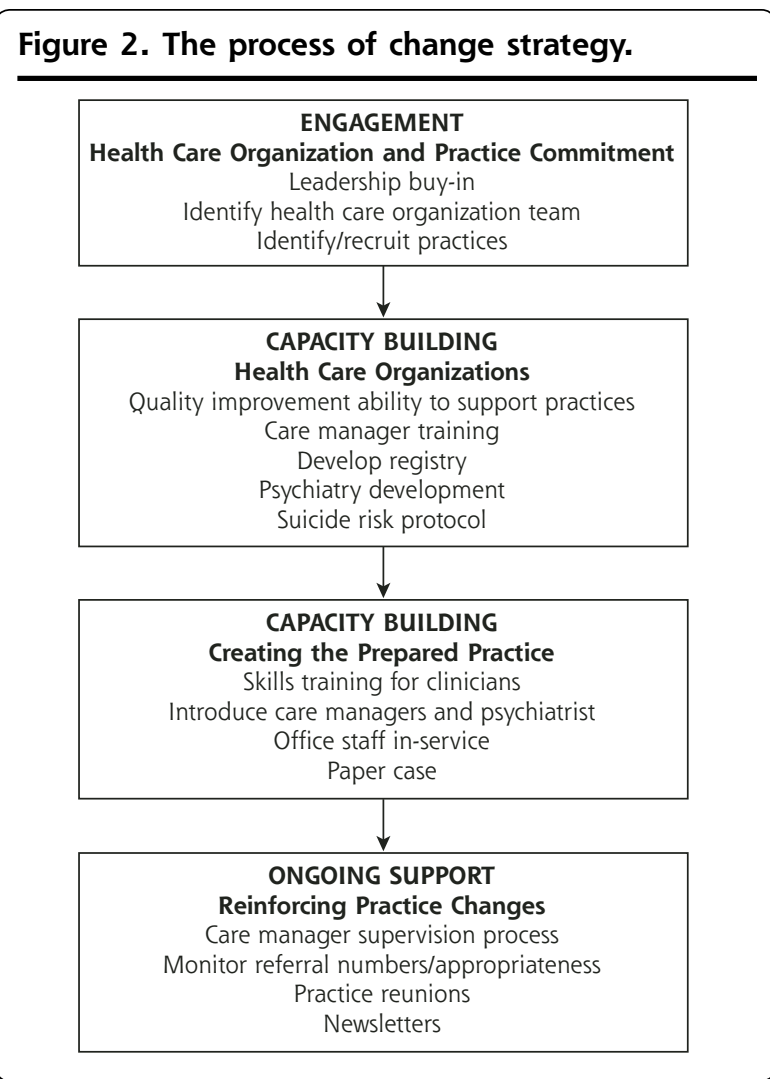

\section{Evaluation}

Clinician surveys and care manager logs describe the process of care. Clinical progress is assessed using PHQ-9. For the RCT, depression severity and functional health of patients are determined at baseline, 3 months, and 6 months through telephone interviews conducted by independent evaluation center staff using validated instruments. ${ }^{33,34}$ Care manager logs and $\mathrm{HCO}$ administrative data are used to assess cooperation with implementation and changes in the process of care in each practice. For a more complete description, see Appendix 5, available online only as supplemental

data at http://www.annfammed.org/cgi/content/ full full/2/4/301/DC 1 .

\section{RESULTS}

Six HCOs initially agreed to serve as collaborating institutions: 3 medical groups and 3 insurance plans, 1 of which is a behavioral health network. These HCOs were recruited to reflect the diversity of organizations nationally and because of their interest in enhancing depression care. One HCO dropped out as a result of leadership changes before enrolling patients in the RCT. The remaining 5 organizations, which engaged 60 practices and 180 clinicians in the RCT, have more than 700 practices and 1,700 clinicians as potential targets for the clinical care model.
All assigned practices were able to implement the TCM. Nine hundred eighty-seven consenting patients were referred to the evaluation center. Of these, 433 were eligible for the evaluation cohort and completed baseline interviews. Appendix 6 (available online only as supplemental data at http://www.annfammed.org/ cgi/content/full/2/4/301/DC1) provides more detail.

\section{DISCUSSION}

The RESPECT-Depression project is evaluating the ability of the practice change strategy to sustain and disseminate the evidence-based clinical model. The clinical model has so far been used with hundreds of patients in the intervention practices, with implementation support provided by the 5 HCOs. An evaluation cohort of depressed patients will allow assessment of 6-month depression outcomes in initial practices late in 2003, and sustainability and dissemination results will be available in 2004-2005.

To our knowledge, the RESPECT-Depression project is among the first to link a randomized controlled trial to subsequent dissemination. The RESPECTDepression project does require new care management resources, as well as a supportive role from psychiatrists, but the $5 \mathrm{HCOs}$ have indicated a willingness to maintain these supports using their own resources. Finally, the RESPECT-Depression project relies on a widely available resource, quality improvement programs of health care organizations, to help clinicians and practices make the jump from the page to the practice in implementing the enhanced model of care. Additional discussion is available online only as supplemental data in Appendix 7 at http://www. annfammed.org/cgi/content/full/2/4/301/DC1).

The RESPECT-Depression project will add to the knowledge base about effective management of depression in primary care. Materials needed to build clinician and care manager capacity to apply the clinical model are available at http://www.depressionprimarycare.org, as are materials needed by quality improvement offices to support its implementation through the change strategy.

These materials and the manuals that support their use allow a turnkey approach to implementation in which a simple system has been engineered to accomplish a complex task using proven methods that allow customization. Clinicians supported by quality improvement infrastructures should demand support for implementing such evidence-based practice enhancements. In addition, this project will contribute to the development of research methods that address translation, sustainability, and dissemination of innovations in primary care. In so doing, it helps set the stage 
for a new generation of research studies using quality improvement structures to support sustained and widespread application of evidence-based best practices.

To read or post commentaries in response to this article, see it online at http://www.annfammed.org/cgi/content/full/2/4/301.

Key words: Depression; depressive disorder; health services research program evaluation; primary health care; information dissemination; randomized controlled trials

Submitted May 28, 2003; submitted, revised, August 25, 2003; accepted October 12, 2003.

Presented in part at Beyond the Clinic Walls: Expanding Mental Health, Drug and Alcohol Services Research Outside the Specialty Care System, sponsored by NIMH, NIDA, NIAA, March 11, 2003, Washington, DC.

Funding support: This research is sponsored by the John D. and Catherine T. MacArthur Foundation.

\section{References}

1. Depression in Primary Care: Treatment of Major Depression. Vol 2. Rockville, Md: Agency for Health Care Policy and Research, US Departmen of Health and Human Services; 1993. Publication AHCPR 93-0511.

2. US Department of Health and Human Services (DHHS), Mental Health: A Report of the Surgeon General. Rockville, Md; US Department of Health and Human Services; 1999.

3. Katon W, Von Korff M, Lin E, et al. Collaborative management to achieve treatment guidelines: Impact on depression in primary care. JAMA. 1995;273:1026-1031.

4. Katon W, Robinson $\mathrm{P}$, Von Korff $\mathrm{M}$, et al. A multifaceted intervention to improve treatment of depression in primary care. Arch Gen Psychiatry. 1996;53:924-932.

5. Wells KB, Sherbourne C, Schoenbaum M, et al. Impact of disseminating quality improvement programs for depression in managed primary care. JAMA. 2000;283:212-220.

6. Hunkeler E, Meresman J, Hargreaves W, et al. Efficacy of nurse telehealth care and peer support in augmenting treatment of depression in primary care. Arch Fam Med. 2000;9:700-708.

7. Simon GE, VonKorff M, Rutter C, Wagner E. Randomised trial of monitoring, feedback, and management of care by telephone to improve treatment of depression in primary care. BMJ. 2000;320:550-554.

8. Katzelnick DJ, Simon GE, Pearson SD, et al. Randomized trial of a depression management program in high utilizers of medical care. Arch Fam Med. 2000:9:345-351.

9. Rost K, Nutting P, Smith JL, Elliott CE, Dickinson M. Managing depression as a chronic disease: a randomised trial of ongoing treatment in primary care. BMJ. 2002;325:934-937.

10. Unützer J, Katon W, Callahan CM, et al. Collaborative care management of late-life depression in primary care: a randomized controlled trial. JAMA. 2002:288:2836-2845.

11. Schulberg HC, Block MR, Madonia MJ, et al. Treating major depression in primary care practice. Eight-month clinical outcomes. Arch Gen Psychiatry. 1996,53:913-919.

12. Dietrich AJ. The telephone as a new weapon in the battle against depression. Eff Clin Pract. 2000;4:191-193.

13. Nutting PA, Rost $K$, Dickinson $M$, et al. Barriers to initiating depression treatment in primary care practice. J Gen Intern Med. 2002;17:103-111.
14. Solberg LI, Fischer LR, Wei F, et al. A CQI intervention to change the care of depression: a controlled study. Eff Clin Pract. 2001;4:239-249.

15. Kroenke K, Taylor-Vaisey A, Dietrich AJ, Oxman TE. Interventions to improve provider diagnosis and treatment of mental disorders in primary care: a critical review of the literature. Psychosomatics 2000;41:39-50

16. Learman LA, Gerrity MS, Field DR, van Blaricom A, Romm J, Choe J. Effects of a depression education program on residents' knowledge, attitudes, and clinical skills. Obstet Gynecol. 2003;101:167-174.

17. Oxman TE, Dietrich AJ, Williams JW, Kroenke K. The Three Component Model of depression management in primary care. Psychosomatics. 2002;43:441-450.

18. Williams JW, Rost K, Dietrich JW, Ciotti MC, Zyzanski SJ, Cornell J. Primary care physicians' approach to depressive disorders: effects of physician specialty and practice structure. Arch Fam Med. 1999;8:58-67.

19. Gerrity MS, Cole SA, Dietrich AJ, Barrett JE. Improving the recognition and management of depression: is there a role for physician education? J Fam Pract. 1999;48:949-957.

20. Gerrity MS, Williams JW, Dietrich AJ, Olson AL. Identifying physicians likely to benefit from depression education: a challenge for health care organizations. Med Care. 2001;39:856-866.

21. Cole S, Raju M, Barrett J, Gerrity M, Dietrich A. MacArthur Foundation depression education for primary care physicians: background, participant's workbook, and facilitator's guide. Gen Hosp Psychiatry. 2000;22:299-358.

22. Williams JW, Barrett J, Oxman T, et al. Treatment of dysthymia and minor depression in primary care: a randomized controlled trial in older adults. JAMA. 2000;284:1519-1526.

23. Barrett JE, Williams JW, Oxman TE, et al. Treatment of dysthymia and minor depression in primary care: a randomized trial in patients aged 18 to 59 years. J Fam Pract. 2001;50:405-412.

24. Pigone MP, Gaynes BN, Rushton JL, et al. Screening for depression in adults: a summary of the evidence for the U.S. Preventive Services Task Force. Ann Intern Med. 2002;136:765-776.

25. Greer AL. The state of the art versus the state of the science. The diffusion of new medical technologies into practice. Int J Technol Assess Health Care. 1988;55:5-26.

26. Spitzer RL, Kroenke K, Williams JBW, et al. Validation and utility of a self-report version of PRIME-MD: the PHQ primary care study. JAMA. 1999;282:1737-1744.

27. Kroenke K, Spitzer RL, Williams JBW. The PHQ-9: validity of a brief depression severity measure. J Gen Intern Med. 2001;16:606-613.

28. Kroenke K, Spitzer RL. The PHQ-9: a new depression and diagnostic severity measure. Psychiatr Ann. 2002;32:509-521.

29. Dietrich AJ, O'Connor GT, Keller A, Carney PA, Levy D, Whaley FS. Improving cancer early detection and prevention: a community prac tice randomized trial. BMJ. 1992;304:687-691.

30. Jackson R, O'Donnell $L$, Johnson $C$, et al. Office systems intervention to improve DES screening in managed care. Obstet and Gynec. 2000;96:380-384.

31. Bordley WC, Margolis PA, Stuart J, Lannon C, Keyes L. Improving preventive service delivery through office systems. Pediatrics. 2001;108:e41.

32. Rogers EM. Diffusion of Innovations. 5th ed. New York, NY: The Free Press; 2003.

33. Derogatis L, Rickels K, Uhlenhuth E, et al. The Hopkins Check List: a measure of primary symptoms. In Pichot P, ed. Psychological Measurements in Psychopharmacology: Problems in Psychopharmacology. Basel, Switzerland: Kargerman; 1974:79-110.

34. Epping-Jordan J, Ustun T. The WHODAS-II: leveling the playing field for all disorders. WHO Mental Health Bulletin. 2000;6:5-6. 